MONS. KRZYSZTOF NYKIEL

Pontificia Universidad Gregoriana, Roma

\title{
LAS INDULGENCIAS: SIGNIFICADO Y ACTUALIDAD PARA LA VIDA DE LA IGLESIA
}

Sumario: Introducción. - 1. Competencia de la Penitenciaría Apostólica en materia de indulgencias. - 2. La Constitución Apostólica del Beato Pablo VI Indulgentiarum Doctrina del 1 de enero ee 1967. - 3. Normativa vigente sobre las indulgencias. - 4. Concesiones de indulgencias. - Conclusión.

\section{Introducción}

En una Audiencia general totalmente dedicada al tema de las indulgencias, San Juan Pablo II dijo en la Plaza de San Pedro: “... En el actual marco ecuménico, la Iglesia siente la exigencia de que esta antigua práctica, entendida como expresión significativa de la misericordia de Dios, se comprenda y acoja bien" ${ }^{1}$. El punto de partida para comprender las indulgencias es la abundancia de la misericordia de Dios, manifestada en la Cruz de Cristo. Jesús crucificado es la gran "indulgencia" que el Padre ha dado a la humanidad, mediante el perdón de las culpas y la posibilidad de la vida filial (cfr. Jn 1, 12-13) en el Espíritu Santo (cfr. Gal 4, 6; Rm 5, 5; 8, 15-16). Y al final de la Proposición n. 7, de la XI Asamblea General Ordinaria del Sínodo de los Obispos, convocada por Su Santidad Benedicto XVI, del 2 al 23 de octubre de 2005, como conclusión del Año de la Eucaristía, se lee: "La renovación de la espiritualidad eucarística puede ser la ocasión para profundizar la comprensión y la práctica de las indulgencias. Este

\footnotetext{
${ }^{1}$ Audiencia General del 29 de septiembre de 1999, L’Osservatore Romano, 30 de septiembre de 1999.
} 
Sínodo recuerda a los Obispos y a los párrocos que pueden pedir a la Penitenciaría Apostólica la indulgencia plenaria para la celebración de diversas ocasiones o aniversarios. El Sínodo aconseja una cate-

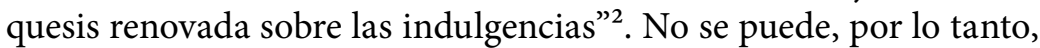
justificar un silencio en esta materia, ni por motivos pastorales, ni por motivos ecuménicos ${ }^{3}$. Los Pastores de almas tendrán que responder a esta llamada insistente de la Iglesia y explicar el significado de las indulgencias, que San Juan Pablo II había definido como "don total de la misericordia de Dios"4. Los ministros ordenados en el desempeño de su ministerio, están invitados no sólo a exponer a los fieles las grandes ventajas espirituales de la práctica de las indulgencias, sino también - cada vez que lo exija vuestro ministerio - acudir a la Penitenciaría Apostólica para implorar el don de las indulgencias.

Ciertamente a fines del 1400 e inicios del 1500, hubo predicadores de las indulgencias que cometieron abusos, particularmente en Alemania, donde hubo una dura confrontación entre los predicadores de las indulgencias papales, para favorecer la reconstrucción de la Basílica de San Pedro, y los poderes locales, entre ellos Federico de Wittenberg, el poderoso protector de Lutero, que había acumulado en su castillo 17.413 reliquias de santos ${ }^{5}$. La respuesta pastoral fue dada por el Concilio de Trento que, por un lado, insistió en la gran utilidad de las indulgencias y recomendó el uso de ellas a todos los fieles, por otro lado, recomendó a los Obispos la moderación en las concesiones. Mientras definía solemnemente que, con el Poder de las Llaves, la Iglesia posee también el de conceder verdaderamente las sagradas indulgencias, dejaba también abiertas muchas cuestiones para una profundización futura ${ }^{6}$. Esta profundización tuvo como

\footnotetext{
${ }^{2}$ Cfr. Notitiae 41(2005) 442.

${ }^{3}$ Cfr. J.-M. Gervais, Profondo significato e scopo pastorale delle Indulgenze, L'Osservatore Romano, 31 de agosto - $1^{\circ}$ de septiembre de 1998.

4 «..totum ipsum donum Dei misericordiae» (Joannes Paulus II, Aperite portas Redemptori, 8, AAS 75 (1983) 98).

${ }^{5}$ Cfr. J. Delumeau, Naissance et affirmation de la Réforme, Paris 1973, p. 83.

${ }^{6}$ Sess. 25, Decretum de Indulgentiis, 4 dic. 1563, DZ 1835.
} 
protagonistas, cuatro siglos más tardes, al Beato Pablo VI y a la Penitenciaría Apostólica.

\section{Competencia de la Penitenciaría Apostólica en materia de indulgencias}

La historia de la Penitenciaría Apostólica está estrechamente relacionada con la de las peregrinaciones a Roma. La más solemne, es el peregrinación del "Año Santo" a Roma ${ }^{7}$. Siempre se le ha encomendado a la Penitenciaría Apostólica la exquisita finalidad espiritual del Año Santo: la Penitencia y las indulgencias, porque ellas "están estrechamente relacionadas con los efectos del sacramento de la Penitencia" ${ }^{8}$. Es por este motivo que el Código de Derecho Canónico, promulgado por el Papa Benedicto XV, colocó a las indulgencias al final del capítulo sobre el sacramento de la Penitencia9. También el Código de $1983^{10}$ y el Catecismo de la Iglesia Católica ${ }^{11}$.

Pero el Concilio de Trento, por motivos de carácter práctico, encomendó la concesión de las otras indulgencias a un dicasterio "ad hoc": la Sagrada Congregación para las indulgencias y Reliquias ${ }^{12}$. San Pío X unió esta Congregación a la Sagrada Congregación de los Ritos el 28 de enero de $1904^{13}$ y finalmente la suprimió el 29 de junio de 1908, cuando concedió al Santo Oficio la competencia sobre las

${ }^{7}$ Cfr. U. Todeschini, La Penitenzieria, un organismo a servizio dei confessori e dei penitenti; J.-M. GervaIs, Le indulgenze e gli Anni Santi in prospettiva storica. Il perdono pienissimo. Riflessioni pastorali circa la Bolla di Indizione del Grande Giubileo del 2000, editado por Jorge Rodríguez, LEV, 1999, p. 23-29.

${ }^{8}$ CCE 1471.

${ }^{9}$ Tit. IV, De poenitentia, Cap. V, De indulgentiis.

${ }^{10}$ Tit. IV, De sacramento paenitentiae, Cap. IV, De indulgentiis.

${ }^{11}$ Art. 4, Sacramentum Poenitentiae et Reconciliationis, n. 10, Indulgentiae.

${ }^{12}$ Conc. Oecum. Trident., Sess. 21, De Indulgentiis. La Congregación para las Sagradas indulgencias y las Reliquias fue hecha perpetua el 6 de julio de 1669 por el Papa Clemente IX.

${ }^{13}$ M.p. Quae in Ecclesiae bonum, 28 de enero de 1904 (cfr. Pii X Pontificis Maximi Acta, 1, 141-144). 
indulgencias ${ }^{14}$. Benedicto XV, el 25 de marzo de 1917, siguiendo la clara orientación de la ley canónica, que daba cada vez mayor relevancia la estrecha conexión entre Penitencia e indulgencias, encomendó definitivamente la Sección de las indulgencias a la Penitenciaría Apostólica, limitando así la competencia del Santo Oficio a los aspectos doctrinales de las nuevas oraciones y devociones ${ }^{15}$. Está competencia de la Penitenciaría Apostólica sobre el uso y la concesión de las indulgencias fue confirmada por el Beato Pablo VI, después del Concilio Vaticano II, ${ }^{16}$ y por San Juan Pablo II, en la Constitución Pastor Bonus ${ }^{17}$.

En consecuencia, la Penitenciaría Apostólica actúa en dos modos diversos ${ }^{18}$ :

a) el modo judicial, como un verdadero tribunal (es el primer tribunal de la Iglesia) ${ }^{19}$ para tratar casos del fuero interno, presentados

\footnotetext{
${ }^{14}$ El Santo Oficio, durante los pocos años de transición había heredado después de la supresión de la Congregación para las indulgencias y las Reliquias, la Sección de las indulgencias, cfr. Const. Apost. Sapienti Consilio, 29 de junio de 1908, I, $1^{\circ}$, 3 , ASS 41 (1908) 427. La competencia sobre las sagradas reliquias fue encomendada a la Sagrada Congregación de los Ritos, cfr. Sapienti Consilio, I, 8 , 3, ASS 41 (1908) 433.

${ }^{15}$ Benedictus XV, M.p. Alloquentes proxime, 25 de marzo de 1917, nn. 4-5, AAS 9 (1917) 167. Benedicto XV, cuando suprimía la S. Congr. del Indice, dándole la competencia al S. Oficio, del mismo S. Oficio, que tenía una enorme cantidad de trabajo muy importante, le quitó la Sección de las indulgencias para unirla, finalmente, a la Penitenciaría Apostólilca, «salvo iure S. Officii videndi ea quae doctrinam dogmaticam circa novas orationes et devotiones respiciunt».

${ }^{16}$ Paulus VI, Const. Apost. Regimini Ecclesiae Universae, 15 de agosto de 1967, n. 113, AAS 59 (1967) 923.

${ }^{17}$ Joannes Paulus II, Const. Apost. Pastor Bonus, 28 de junio de 1988, art. 120, AAS 80 (1988) 890.

${ }^{18}$ Hasta el año 1971 el personal de la Secretaría estaba dividido en dos secciones. En 1977 fue reducido al mínimo histórico: sólo dos Oficiales menores (un Ayudante de estudio y un Agregado o secretario, con encargo de escritor y archivista).

${ }^{19}$ Sapienti Consilio (II, 1-3): $1^{\circ}$ Sacra Poenitentiaria, $2^{\circ}$ Sacra Romana Rota, $3^{\circ}$ istitución de la Signatura Apostolica (después de la supresión de los tribunales de la Signatura papalis gratiae et iustitiae); Regimini Ecclesiae Universae (VI, 104-113: los tribunales son colocados después de los Secretariados, el Consejo para los laicos y la Pontificia Comisión "a iustitia et pace" ): $1^{\circ}$ Supremum Tribunal Signaturae
} 
habitualmente por medio del confesor que es el interlocutor privilegiado para actuar en nombre del penitente ${ }^{20}$

b) el segundo modo es el heredado de la Congregación de las Sagradas indulgencias, siempre con la aprobación del obispo diocesano o del superior religioso.

\section{La Constitución Apostólica del Beato Pablo VI Indulgentiarum Doctrina del 1 de enero de 1967}

La Constitución Apostólica Indulgentiarum Doctrina del Beato Pablo VI fue publicada el $1^{\circ}$ de enero de $1967^{21}$. En la elaboración de este documento participó directamente la Penitenciaría Apostólica, tanto en la parte doctrinal, la más extensa, como en la parte normativa. La Indulgentiarum Doctrina es una síntesis muy articulada sobre la doctrina de las indulgencias. Ella es citada en el breve pero importante capítulo sobre las indulgencias en el Catecismo de la Iglesia Católica. Es muy recomendable la lectura y la meditación de este solemne documento del Beato Pablo VI, que es encuentra al final del Enchiridion Indulgentiarum.

La Constitución Indulgentiarum Doctrina comienza con la siguiente afirmación: “ La doctrina y uso de las indulgencias, vigentes en la Iglesia católica desde hace muchos siglos están fundamentados sólidamente en la revelación divina" ${ }^{\text {22 }}$. El documento, de hecho, no ha cambiado ni podía cambiar la doctrina sobre las indulgencias, porque - como afirmó el Cardenal Ciappi, que participó directamente

\footnotetext{
Apostolicae, $2^{\circ}$ Sacra Romana Rota, $3^{\circ}$ Sacra Paenitentiaria Apostolica; Pastor Bonus (IV, 117-130: los tribunales preceden los pontificios consejos): $1^{\circ}$ Paenitentiaria Apostolica, $2^{\circ}$ Supremum Tribunal Signaturae Apostolicae, $3^{\circ}$ Tribunal Rotae Romanae.

${ }^{20}$ Es una norma procedural de la Penitenciaría Apostólica. Il c. 1048 del CIC lo exige explícitamente para la dispensa de las irregularidades: «...firmo tamen manente onere quam primum recurrendi ad Ordinarium aut Paenitentiariam, reticito nomine et per confessarium».

${ }^{21}$ Const. Apost. Indulgentiarum Doctrina, $1^{\circ}$ ian. 1967, AAS 59 (1967) 5-24. Cfr. E. Mura, Constitutionis Apostolicae Indulgentiarum Doctrina breve commentarium, Città del Vaticano 1967.

${ }^{22}$ ID 1.
} 
en la reforma de Pablo VI - "se trata de una doctrina de la fe, que Dios mismo ha revelado en sus fundamentos"23. Y advertía: “... rechazar o disminuir la doctrina tradicional sobre las indulgencias,... equivaldría a rechazar o extenuar los dogmas de la solidaridad de los hombres redimidos con Cristo; de la Comunión de los Santos; del valor infinito de los méritos de Cristo... (cfr. Summa Theol., Suppl., q. 25, a. 1); del Poder de las Llaves...; de la infabilidad de los Concilios Ecuménicos, del Romano Pontífice y del Magisterio ordinario universal".

La doctrina de las indulgencias se funda esencialmente sobre tres realidades conocidas por la fe:

a) una deuda, con la posible persistencia - incluso después de la Confesión sacramental - de la pena temporal del pecado, que hay que expiar ya sea en esta vida o en el purgatorio ${ }^{24}$;

b) un tesoro, del cual la Iglesia es dispensadora, constituido por las expiaciones y méritos de Cristo, además de las oraciones de la Santísima Virgen y de todos los santos ${ }^{25}$;

c) un intercambio de bienes espirituales en la comunión de los santos, gracias a la solidaridad sobrenatural en el Cuerpo Místico de Cristo ${ }^{26}$.

La definición de indulgencia, propuesta por la Constitución Indulgentiarum Doctrina es ya clásica ${ }^{27}$ : se puede encontrar también sucesivamente en el Manual de las indulgencias ${ }^{28}$, en el Código de Derecho Canónico $^{29}$, en el Catecismo de la Iglesia Católica ${ }^{30}$ : "indulgencia es la remisión ante Dios de la pena temporal por los pecados, ya perdonados en lo referente a la culpa que gana el fiel, convenientemente preparado, en ciertas y determinadas condiciones, con la ayuda de la

${ }^{23}$ L. CiAPPI, Concilio e riforma delle indulgenze, Vita Religiosa 2 (1967) 99-108; cfr. también, Tradizione e novità nella riforma delle indulgenze, L'Osservatore Romano, 9-10 de enero de 1967, 2.

${ }^{24}$ Cfr. ID 3.

${ }^{25} \mathrm{Cfr}$. ID 5 .

${ }^{26}$ Cfr. ID 5.

${ }^{27}$ ID, norma 1.

${ }^{28}$ Enchiridion Indulgentiarum (EI) 1968, norma 1; 1986, norma 1; 1999, norma 1.

${ }^{29}$ CIC, can. 992.

${ }^{30}$ CCE 1471. 
Iglesia, que, como administradora de la redención, dispensa y aplica con plena autoridad el tesoro de los méritos de Cristo y de los santos".

Las indulgencias, por lo tanto, son muy útiles para la vida espiritual del fiel cristiano: ayudan en la lucha contra el pecado y las fuerzas del mal, promueven la caridad y ofrecen una preciosa ayuda a todos los hermanos difuntos; despiertan la esperanza de una plena reconciliación con Dios Padre, refuerzan la comunión jerárquica entre los fieles y los pastores y, sobre todo, con el Vicario de Cristo, contribuyendo a que la Iglesia se presente santa e inmaculada, unida en Cristo en el vínculo de la caridad.

\section{Normativa vigente sobre las indulgencias}

La normativa actual sigue los cuatro principios ${ }^{31}$ :

a) Para favorecer el espíritu de piedad y el fervor de la caridad, la medida de la indulgencia parcial es proporcionada a la recta intención del fiel, quitando toda referencia a los días u años de las antiguas penitencias canónicas ${ }^{32}$.

b) Para exhortar a una seria preparación interior, la indulgencia plenaria se limita - para los fieles - a sólo una en el día, con el cumplimiento de tres condiciones (Confesión sacramental, Comunión eucarística y oración según las intenciones del Sumo Pontífice).

c) Para evitar todo peligro de superstición en materia de objetos de piedad, la indulgencia depende ahora del uso pío que se haga de ellos y no del hecho puramente material de tenerlos consigo.

${ }^{31}$ Sacra Paenitentiaria Apostolica, Prot. N. 2633/65, Positio de Sacrarum Indulgentiarum recognitione. Relatio super schema de Indulgentiis recognoscendis, Città del Vaticano 1965. Por la traducción italiana, cfr. G. CAPRILE, Il Concilio Vaticano II. Cronache del Concilio Vaticano II edite da "La Civiltà Cattolica", 5, Roma, 1969, p. 354-357; J.-M. GervaIs, Paolo VI e la riforma della disciplina delle indulgenze, Periodica 88 (1999) 301-329.

${ }^{32}$ La cuenta en días y años se refería a la antigua penitencia canónica, es decir, in foro Ecclesiae; pero desde hace muchos siglos la Iglesia, concediendo las indulgencias, entiende remitir la pena temporal del pecado no sólo en el fuero eclesiástico, sino verdaderamente frente a Dios (in foro Dei). 
d) Para reafirmar la centralidad de la celebración eucarística, fue abolida la indulgencia del "Altar Privilegiado", que hacía una discriminación no sólo entre los altares, sino también entre los sacerdotes ${ }^{33}$.

El 29 de junio de 1968 fue promulgado el Enchiridion Indulgentiarum que se puede considerar como un compendio de todas las disposiciones vigentes en materia de indulgencias, aplicables a los fieles latinos y orientales ${ }^{34}$. En este breve ensayo, me limitaré a exponer en modo práctico, las condiciones para ganar las indulgencias, las facultades de los confesores en materia de indulgencias, y la aplicabilidad del don de las indulgencias.

a) Sujeto capaz de lucrar las indulgencias y las condiciones que se requieren

Para lucrar las indulgencias es necesario:

a) ser bautizado, no excomulgado, en estado de gracia, al menos al fin de la obra prescrita ${ }^{35}$,

b) tener la intención al menos general de ganar las indulgencias, cumplir "las obras impuestas en el tiempo y en el modo establecido" ${ }^{\text {. }}$ Ello basta para las indulgencias parciales, pero no para las plenarias. Para ganar efectivamente una indulgencia plenaria, existe un principio fundamental, oportunamente recordado por San Juan Pablo II: la "condición espiritual para recibir la indulgencia plenaria es la exclusión de todo afecto hacia cualquier pecado, incluso el venial" ${ }^{37}$.

Decía San Juan Pablo II que las indulgencias, lejos de ser una especie de "descuento" de la obligación de convertirse, son más bien una ayuda para un compromiso más generoso y más radical”. Además de la plena disposición, más bien para procurarla, la Iglesia agrega

\footnotetext{
${ }^{33}$ indulgencia plenaria, que era aplicada por el celebrante al alma del difunto por el cual celebraba la Misa. El altar privilegiado podía ser local, personal o mixto; perpetuo o ad tempus; cotidiano o no (cfr. CIC 1917, can. 918, \$ 1). Los Cardenales gozaban del altar privilegiado personal cotidiano (CIC 1917, can. 219, $\$ 1,10^{\circ}$ ).

${ }^{34}$ Es por lo tanto un código único en su género.

${ }^{35} E I$, norma $17, \$ 1$.

${ }^{36} E I$, norma $17, \S 2$.

${ }^{37}$ Audiencia general del 29 de septiembre de 1999.
} 
tres condiciones necesarias: la Confesión sacramental, la Comunión eucarística, y la oración según las intenciones del Sumo Pontífice ${ }^{38}$. La práctica de las indulgencias reafirma la necesidad de las mediación de la Iglesia y la necesidad de la participación en los sacramentos ${ }^{39}$.

Antes que nada, el sacramento de la Penitencia o Reconciliación. Para la indulgencia plenaria es necesaria la Confesión frecuente, sin la cual no se puede tener una verdadera vida espiritual ${ }^{40}$. Cada indulgencia plenaria, además, está unida al sacramento de la Eucaristía, "fuente y cumbre de toda la vida cristiana" ${ }^{41}$. En fin, cada indulgencia plenaria exige la oración según las intenciones del Sumo Pontífice ${ }^{42}$. Recibiendo las indulgencias, los fieles participan eficazmente en la edificación de la Iglesia, en unión con el Vicario de Cristo.

\section{b) Facultades de los confesores}

Los confesores tienen la facultad de intervenir en favor de los fieles legítimamente impedidos de cumplir con alguna condición o de completar la obra indulgenciada ${ }^{43}$. El Enchiridion dice: "Los confesores pueden conmutar tanto la obra prescrita como las condiciones, en favor de aquellos que, debido a un legítimo impedimento, no pueden ponerlas en práctica" ${ }^{34}$. Se puede ejercitar esta facultad incluso fuera de la Confesión. La conmutación más frecuente será ciertamente la de la Comunión para los enfermos. Puesto que no es una dispensa, sino una conmutación, es conveniente aconsejar al enfermo o al anciano al menos la Comunión espiritual.

\footnotetext{
${ }^{38}$ EI, norma 20.

${ }^{39}$ La recepción de los sacramentos de la Penitencia y de la Eucaristía son "condiciones" para lucrar una indulgencia plenaria, y no son "las obras indulgenciadas".

${ }^{40} E I$, norma 20, $\$ 3$ : La Confesión puede ser hecha en el mismo día en que realiza la obra, o algunos días antes (hasta 20). Cfr. Penitenzieria Apostolica, Il dono dell'Indulgenza, 29 de enero 2000 (L'Osservatore Romano, 10 febbraio 2000).

${ }^{41}$ Cfr. EI, norma 20, $\$ 2$.

${ }^{42} E I$, n. $20, \S 2$.

${ }^{43}$ Cfr. J.-M. Gervais, L'acquisto dell'indulgenza giubilare da parte dei malati e degli altri fedeli legittimamente impediti, L'Osservatore Romano, 11 febbraio 2000.

${ }^{44} E I$, n. 24.
} 
c) Aplicación de las indulgencias. ¿Por sí mismo y por los demás, por los vivos y por los difuntos?

En cuanto a la aplicabilidad de las indulgencias, se recuera que antes de la reforma del Beato Pablo VI, sólo las indulgencias concedidas por el Sumo Pontífice podían ser aplicadas a los difuntos ${ }^{45}$. Con la normativa vigente, todas las indulgencias, incluso aquellas concedidas por los cardenales, patriarcas, metropolitas, y obispos, pueden ser aplicadas a los difuntos en sufragio, es decir, por intercesión, como cuando se celebra por ellos la Santa Misa ${ }^{46}$. Un fiel, sin embargo, no puede aplicar una indulgencia por otro fiel vivo. La razón es una consecuencia del vínculo que hay entre el sacramento de la Penitencia y la indulgencia, siempre confirmado por la doctrina y la ley canónica. No podemos recibir la absolución sacramental en lugar de otros, confesando sus presuntos pecados. En otras palabras, la indulgencia para los vivos, que están en condiciones de merecer o desmerecer, depende de un acto de la propia voluntad en lugar del cumplimiento de las otras condiciones. Para los difuntos es totalmente distinto: en este caso la aplicación se hace en modo analógico, es decir, como sufragio, y siempre con el beneplácito de Dios.

\section{Concesiones de indulgencias}

a) El Enchiridion Indulgentiarum y las cuatro concesiones generales

Las concesiones universales son antes que nada las del Enchiridion Indulgentiarum o Manual de las indulgencias ${ }^{47}$. En él, las ocasiones para la indulgencia son múltiples ${ }^{48}$. Para la indulgencia parcial, es decir, la que remite sólo una parte de la pena temporal, además de las oraciones recomendadas por la Iglesia, basta recordar en este

\footnotetext{
${ }^{45}$ Cfr. CIC 1917, can. 913, $2^{\circ}$.

${ }^{46}$ EI, norma 3.

${ }^{47}$ En el Pontificado del Papa Pablo VI fueron publicadas dos ediciones del Enchiridion Indulgentiarum. La tercera fue en el año 1986.

${ }^{48}$ Cfr. J.-M. Gervais, La quarta edizione dell'Enchiridion Indulgentiarum, Ius Ecclesiae 12 (2000) 173-187.
} 
momento las cuatro concesiones generales, que son el fundamento de la reforma del Beato Pablo VI y que se encuentran al comienzo del Enchiridion Indulgentiarum.

Esas sirven para dar el tono a la vida cristiana de cada día. Con la primera, los fieles son alentados a seguir el mandato del Señor: "Es necesario orar siempre, sin desfallecer" ${ }^{49}$. Con la segunda, el fiel es inducido, con el ejemplo y por mandato de Cristo, a cumplir los más frecuentemente posible, obras de caridad y de misericordia ${ }^{50}$. Con la tercera, el fiel es impulsado a frenar las pasiones, a reducir en esclavitud su cuerpo y a conformarse con Cristo, pobre y paciente ${ }^{51}$. La cuarta concesión exhorta al fiel a dar testimonio abiertamente su fe a los otros, para la gloria de Dios y la edificación de la Iglesia ${ }^{52}$.

En cuanto a las indulgencias plenarias, es decir, aquellas que remiten la totalidad de la pena temporal, el Enchiridion ofrece una amplia gama, desde el $1^{\circ}$ de enero, con el canto público del Veni, creator, hasta el 31 de diciembre con el del Te Deum ${ }^{53}$.

\footnotetext{
${ }^{49}$ "Se concede indulgencia parcial al fiel cristiano que, en el cumplimiento de sus obligaciones y en el sufrimiento de las dificultades de la vida, eleva su alma a Dios con humilde confianza, añadiendo - aunque sólo sea mentalmente - alguna piadosa invocación».

${ }^{50}$ «Se concede la indulgencia parcial al fiel que, con espíritu de fe y ánimo misericordioso, coloca sí mismo o sus bienes a disposición de los hermanos que se encuentren necesitados».

${ }^{51}$ «Se concede la indulgencia parcial al fiel, que en espíritu de penitencia, se prive espontáneamente y con su sacrificio de alguna cosa lícita».

52 «Se concede la indulgencia parcial al fiel que, en circunstancias particulares de la vida cotidiana, da testimonio de la fe ante los demás».

${ }^{53} 1^{\circ}$ de enero (conc. $26, \S 1,1^{\circ}$; Semana por la unidad de los cristianos (conc. $11, \S 1$; 22 de febrero (conc. 33, $\$ 1,3^{\circ}$ ); todos los Viernes de Cuaresma (conc. 8, $\$ 1,2^{\circ}$ ); el Jueves Santo (conc. 7, $\$ 1,2^{\circ}$ ); el Viernes Santo (conc. 13, $1^{\circ}$ ); el Sábado Santo (conc. $28, \S 1$ ); Pentecostés (conc. $26, \S 1,1^{\circ}$ ); el Cuerpo y la Sangre de Cristo (conc. $7, \S 1$, $3^{\circ}$ ); el Sagrado Corazón de Jesús (conc. 3); SS. Apóstoles Pedro y Pablo (con. 14, \$1; conc. $33, \$ 1,2^{\circ}, 3^{\circ}$ ); 2 de agosto (conc. $33, \$ 1,2^{\circ}, 3^{\circ}, 5^{\circ}$ ); desde el $1^{\circ}$ al 8 de noviembre (conc. 29, $\$ 1,1^{\circ}$ ); Conmemoración de todos los fieles difuntos (conc. 29, $\$ 1,2^{\circ}$ ); 9 de noviembre (conc. $33, \S 1,3^{\circ}$ ); Cristo Rey (conc. 2); 31 de diciembre (conc. $26, \S 1$, $2^{\circ}$.
} 
La indulgencia plenaria se puede lucrar también cotidianamente con la adoración eucarística ${ }^{54}$ o la lectura de la Sagrada Escritura, por al menos una media hora ${ }^{55}$, el rezo devoto del Via $\mathrm{Crucis}^{56}$ y la recitación del santo rosario mariano ${ }^{57}$. Y también en muchas otras circunstancias $^{58}$ incluso en articulo mortis ${ }^{59}$. El uso de las sagradas indulgencias, tanto hoy como en el pasado, se adapta a las circunstancias de los lugares y de los tiempos. Así, mientras por ejemplo en el Medioevo, tal favoreció la realización de muchísimas obras de utilidad pública $^{60}$, hoy no se duda de servirse de la radio o de la televisión, que, bien utilizados, pueden transformarse de medios de comunicación social en canales de comunión eclesial. De este modo, se han agregado a concesiones precedentes concernientes a las bendiciones papales ${ }^{61}$

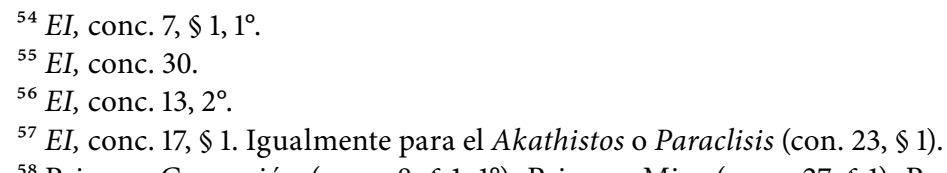

${ }^{58}$ Primera Comunión (conc. $8, \$ 1,1^{\circ}$ ); Primera Misa (conc. 27, $\$ 1$ ); Procesión eucarística (conc. $7, \S 1,3^{\circ}$ ); Celebración jubilar de la Ordenación sacerdotal (conc. $27, \S 2$ ); Congreso eucarístico (conc. $7, \$ 1,4^{\circ}$ ); Ejercicios espirituales (conc. 10, $\$ 1$ ); Sagradas misiones (conc. 16, $\$ 1$ ); Jornadas Mundiales (conc. 5); aniversario del Bautismo (conc. 28, $\$ 1$ ); consagración de la familia (conc. 1); dedicación de una iglesia o altar (conc. $\left.33, \$ 1,6^{\circ}\right) \ldots$

${ }^{59}$ No es necesario que sea inminente el peligro de muerte: «Utrum Benedictio Apostolica cum Indulgentia plenaria in articulo mortis dari possit post collata extrema Sacramenta, quum periculum quidem mortis adest, non tamen imminens? Resp.: Affirmative» (S.C. Indulg., 19 dic. 1885: ASS 18 (1885) 414). La indulgencia, sin embargo, no se gana «in praesumpto» sino «in vero articulo mortis» (S.C. Indulg., 23 aprile 1675; decr. auth. n. 9, ad 1.um). La bendición se da «semel in eodem statu morbi» (S.C. Indulg., 23 sett. 1775, decr. auth. n. 237, ad 6.um); puede ser repetida (S.C. Indulg., 24 sett. 1838, decr. auth. 263 ad 2.um: «Utrum benedictio Apostolica pluries impertiri possit infirmis, novo mortis periculo redeunte? Resp.: Negative, eadem permanente infirmitate etsi diuturna; Affirmative, si infirmus convaluerit, ac deinde quacumque de causa in novum mortis periculum redeat»; cfr. anche S.C. Indulg., 12 feb. 1842, decr. auth. 300).

${ }^{60}$ No solo iglesias, sino también hospitales, escuelas, puentes, calles, etc.

${ }^{61}$ Cuando el Santo Padre o el obispo diocesano imparten la bendición papal, si por una causa razonable, un fiel no puede estar presente físicamente en la ceremonia, 
el Via Crucis y el rosario en unión con el Santo Padre ${ }^{62}$, y también la lectura de la Sagrada Escritura ${ }^{63}$.

\section{b) Otras concesiones}

Así como el Enchiridion Indulgentiarum o Manual de las indulgencias contiene toda la normativa indulgencial y todas las concesiones generales de indulgencias actualmente vigentes, la Penitenciaría responde también todas las preguntas que se le hagan sobre la práctica de las indulgencias y las peticiones que provienen de todo el mundo católico para implorar la indulgencia plenaria con ocasión de eventos eclesiales de particular relevancia, o a favor de grupos de fieles reconocidos canónicamente (por ejemplo, miembros de un instituto de vida consagrada, sociedades de vida apostólica, asociaciones pías) y de lugares sagrados muy apreciados por los fieles.

La Penitenciaría concede la indulgencia por la visita devota de los santuarios más queridos de la devoción popular, normalmente ad septennium excepcionalmente in perpetuum (cuando se reconfirman antiguos privilegios).

Los sacerdotes, como pastores de almas, cuando es necesario o útil para el bien de las almas, pueden dirigirse siempre a la Penitenciaría para la concesión de indulgencias, siempre con la aprobación o consentimiento del Ordinario del lugar. Cuando se trata de una indulgencia parcial, para una oración o para un ejercicio de piedad de difusión local, es conveniente que sea el obispo diocesano que la conceda directamente en su diócesis o el arzobispo metropolitano, en el ámbito de la provincia eclesiástica ${ }^{64}$.

no pierde la indulgencia plenaria si, durante la celebración de los ritos, recibe devotamente la bendición por medio de la radio o de la televisión (EI, conc. 4).

${ }^{62}$ Un fiel puede lucrar la indulgencia plenaria, cuando con devoción se une al rezo del santo rosario o al Via Crucis presidido por el Santo Padre, transmitido por radio o por televisión ( $E I$, conc. $17, \$ 1$ e conc. $13,2^{\circ}$ ).

${ }^{63} \mathrm{Si}$ por enfermedad u otra causa razonable, un fiel no puede leer las Sagradas Escrituras, puede conseguir la indulgencia, meditando el texto sagrado, con la ayuda de instrumentos de video o audio (EI, conc. 30 ).

${ }^{64}$ EI, norme 7-8. 
La indulgencia plenaria habitualmente es concedida en el día de la solemne apertura y de la conclusión de un periodo de tiempo celebrativo, y también para las principales solemnidades o momentos de encuentro. La obra indulgenciada suele consistir en la participación devota en una función jubilar, en una peregrinación colectiva o en una visita pía a un lugar sagrado. Además, la Penitenciaría, siempre sobre el modelo del Jubileo universal, propone también algunas obras de misericordia, penitencia y evangelización particularmente adecuadas a nuestros tiempos y a los fines espirituales de los fieles que imploran la indulgencia. Como motivos válidos para pedir la indulgencia se pueden mencionar la erección de una cofradía ${ }^{65}$; la dedicación de un lugar sagrado; la erección de un santuario (diocesano, nacional, internacional); la bendición de una escala santa o puerta santa; la coronación de la imagen de la Santísima Virgen; un tiempo especial de oración o penitencia (año misional o mariano, novena, triduo, jornada...); una peregrinación comunitario; el traslado solemne de sagradas reliquias o la visita de la Virgen peregrina; la fiesta titular para las iglesias no parroquiales, etc. Las ocasiones son muchas en realidad y la Penitenciaría responde con gusto todas las peticiones, respetando naturalmente la práctica habitual, porque la concesión de indulgencias estimula a la caridad de los fieles, a la digna recepción de los sacramentos y a las obras de misericordia y penitencia. En fin, esta Penitenciaría es el organismo competente para dar respuesta a todas las preguntas y dudas que surjan sobre el uso de las indulgencias.

La indulgencia es también un maravilloso signo de comunión eclesial con el Santo Padre. Llama la atención el aprecio que existe por las indulgencias en los Países donde la religión es perseguida. Los fieles de tales países ven en la indulgencia un vínculo especial con la Santa Sede que ninguna autoridad política estatal puede impedir; la indulgencia en este caso es vivida por los fieles, como una profesión

\footnotetext{
${ }^{65}$ Cfr. J.-M. Gervais, Indulgenze e Confraternite. Gli Elenchi o Sommari di Indulgenze, Confraternite Oggi, 2003, n. 14; Indulgenze e Confraternite. Per eventi significativi per i quali riesce pastoralmente utile chiedere il dono dell'Indulgenza, Confraternite Oggi, 2004, n. 16.
} 
de fe y sobre todo como un signo de comunión con el Santo Padre, que ninguna autoridad política contraria puede impedir. Es claro que las obras indulgenciadas recibidas de este modo no pueden ser jamás prácticas formalistas.

\section{Conclusión}

A la luz de lo que hasta aquí se ha tratado sobre la importancia de las indulgencias para la vida de la Iglesia, es útil insistir que el don de la indulgencia subraya el amor que la Iglesia tiene hacia cada creyente, tomándose la carga del pecado de sus hijos. Con el tesoro de la indulgencia la Iglesia educa al fiel a vivir y a crecer en el amor, para rechazar el pecado y el egoísmo, robusteciendo su vida de fe y de esperanza. Quien recibe este don experimenta la felicidad de la reconciliación, encontrándose con el Amor que perdona y redime. Espero que la presente exposición pueda ayudar a comprender mejor la belleza del don de las indulgencias, su significado y actualidad para la vida espiritual de los fieles, además de incentivar en ellos el deseo de buscar siempre - y no sólo en el Año Santo de la Misericordia - la perfección de la caridad y también de las diversas ocupaciones de la vida cotidiana.

\section{The indulgences: significate and actual influence on the life of the Church}

This paper aims to expose the doctrine on indulgences, its historical evolution, current legislation and actual influence on the life of the Church. The author highlights how the indulgences are useful to the spiritual life of the Christian faithful: they help in the fight against sin and evil forces, they stimulate to charity and they offer a valuable assistance to our deceased brothers and sisters; they awaken the hope of full reconciliation with God the Father; they strengthen the hierarchical communion of the faithful and pastors, and especially with the Vicar of Christ; they contribute so that the Church presents herself as holy and immaculate, united in Christ with the bond of charity. 
Palabras Claves: indulgencia plenaria, indulgencia parcial, Penitenciaría Apostólica, contrición, perdón, Confesión sacramental, confesor, facultad, celebración eucarística, conversión, Sumo Pontífice, obra indulgenciada

KeY wORDs: plenary indulgence, partial indulgence, Apostolic Penitentiary, contrition, forgiveness, sacramental confession, the confessor, the faculty, the Eucharistic celebration, conversion, Supreme Pontiff, indulgenced work

\section{Nota o Autorze:}

Mons. Krzysztof Nykiel - Regente de la Penitenciaria Apostólica, ha conseguido en el 2001 el doctorado en Derecho Canónico en la Pontificia Universidad Gregoriana. Desde el $1^{\circ}$ de octubre de 1995 ha prestado sus servicios en la Santa Sede, primero en el Pontificio Consejo para los Operadores Sanitarios, después en la Congregación para la Doctrina de la Fe, del 2002 al 2012. Desde el $1^{\circ}$ de julio de 2014 es profesor invitado en la Facultad de Derecho Canónico de la Pontificia Universidad Gregoriana. 